\title{
Entrevista
}

\section{Cristian Segura: o artista do desassossego}

Cristian Segura (1976, Argentina)

Segue uma linha de trabalho que compreende estratégias relacionadas com os mecanismos e a variabilidade da arte contemporânea, sempre com um olhar crítico e reflexivo sobre o terreno institucional. Seu interesse pela arte, desde cedo, começou com trabalhos voluntários em museus a partir dos 14 anos. Aos 19 anos, era Coordenador de Exposições e aos 23 anos, Diretor do Museo Municipal de Tandil ${ }^{1}$.

Entrevista concedida por e-mail para as mestrandas Daiana Schvartz e Joana Aparecida da Silveira do Amarante, PPGAV/CEART, fev. 2012.

P. Cristian, vamos começar falando sobre os trabalhos apresentados na Bienal de Curitiba (2011) e o realizado na Residência Artística em Barcelona (2008), que podemos observar a presença de uma pesquisa prévia do lugar, tanto da instituição como da cidade, onde você irá expor. Como acontece essa relação com estes lugares?

R. Cuando recibí la invitación para participar de la Bienal Ventosul viajé a Curitiba para comenzar a pensar mis propuestas de obras. No conocía la ciudad, de modo que todo era nuevo para mí. Me propuse entonces caminar sus calles, usar su transporte, conocer sus monumento y museos, visitar sus lugares recreativos y de esparcimiento, hablar con la gente, leer sus periódicos y conocer sobre su historia, procurando estar bien receptivo de todo ello. Al final del día, al regresar al hotel, revisaba mis notas, fotografías y videos y ampliaba los datos con la Internet y otras fuentes, conservando todo aquello que podía ser interesante y descartando el resto. Al día siguiente, lo hacía de nuevo. Así, intensamente, durante una semana. De este modo, cuando volví a la argentina ya tenía varias ideas, las que organicé a modo de proyecto para producir algunos meses después, in situ, en espacios públicos de la ciudad.

En Barcelona la experiencia de trabajo fue similar pero de mayor duración, casi 2 meses, becado por el Centro de Producción Hangar, donde tenía mi estudio.

\footnotetext{
${ }^{1}$ Informações do portfólio do artista Cristian Segura.
} 
En ambos casos utilicé la metodología de proyecto como forma de trabajo, organizando en dos fases mi plan de actuación. La primera de investigación, mediante un trabajo de campo en el lugar, y la segunda de producción, habiendo formulando una serie de propuestas de obras en base al material obtenido precedentemente y a las conclusiones alcanzadas de su análisis. Es así que los trabajos resultantes estuvieron ligados con el lugar de producción, con el contexto y el tiempo.

\section{P. Fale-nos sobre seus trabalhos realizados na $6^{\text {a }}$ VentoSul, Bienal de Curitiba, em} 2011, onde você fez algumas intervenções em pontos importantes da cidade como a Ópera de Arame e a Praça Tiradentes.

R. Recién llegado a Curitiba visité la feria que cada domingo se realiza a lo largo de una de las calle centrales de la ciudad. Allí comí por primera vez piñón, la semilla del pino, que se ofrecía a unos pocos Reales en uno de los puestos. De regreso al hotel, advertí que el piñón se encontraba también en los diseños con "petit pavé" de algunas veredas. Al día siguiente, observé que en la vegetación local el pino Paraná (Araucaria angustifolia) estaba en los parques, plazas y bosques. Supe, conversando con la gente del lugar, que están protegidas por la legislación ambiental que impide su tala. Todo esto cobró sentido para mí al investigar la etimología del nombre Curitiba. Derivaría de la expresión indígena "cury'i ty (b) ba", que en guaraní significa "lugar donde existen pinos". Más exactamente, "Cury'ï" significa "pino Paraná", y por metonimia el "piñón". De ahí que este símbolo se repita en diferentes partes de la ciudad; inclusive la Araucaria está en el centro de su escudo y de su bandera.

Me pregunté entonces si sería posible producir un "quiebre" en la memoria histórica local y provocar su redescubrimiento mediante una experiencia multisensorial. Fue así que planeé una serie de intervenciones, a modo de circuito narrativo, entre la Praça Tiradentes, el Jardim Botanico y la Opera de Arame.

\section{P. Fale-nos sobre essa narrativa que você cria com 3 intervenções, em lugares distintos da cidade de Curitiba.}

R. La Praça Tiradentes es el punto cero de la ciudad, donde se encuentra el antiguo empedrado que data del Siglo XIX, cubierto por gruesos vidrios que le da visibilidad y lo protege. Este hallazgo arqueológico, descubierto en el año 2008, es un referente fundacional que tiene además, en medio, la Araucaria angustifolia. Sobre estos 119 m2, simulé vidrios rotos, mediante grietas de vinilo adhesivo de color negro. Para el diseño, 
realicé inicialmente una xilografía, la que luego transformé digitalmente a vectores. La xilografía es una técnica de impresión con plancha de madera (material que se puede asociar también con la Araucaria), la que se talla a mano con una gubia. Escogí una técnica de grabado porque tiene una presencia capital en Curitiba. Muestra de ello es que la Casa del Grabado alberga, desde 1989, lo que Leite (2004) considera "o primeiro museu brasileiro e um dos poucos do mundo exclusivamente dedicado à gravura - o Museu da Gravura".

En el Jardim Botanico, la estufa, de estructura metálica y paredes y techo de vidrio, aloja especies botánicas que son referencia nacional. Sobre su exterior diseñé inmensas palabras en guaraní que describen un gran estruendo de cristales rotos, en vinilo adhesivo de color negro. Lo hice usando la estética de las onomatopeyas de comic, porque sirven para representar ruidos. Las palabras que escogí fueron itaverá, empleada en su acepción de "cristal", ya que también se asemeja en su significado a un diamante (itá: piedra; verá: brillante). Sununu (se pronuncia sununú), que significa "trueno", pero puede ser equiparada a "gran ruido" o "estruendo". Y soro que representa "roto" o "quebrado"; el guaraní es generoso con las inflexiones metafóricas y las readaptaciones retóricas.

Y la Opera de Arame, otro símbolos emblemáticos de Curitiba, cuya materialidad dialoga con las ya mencionadas en su estructura metálica recubierta de vidrio. Tiene capacidad para 1572 espectadores que desde sus lugares ven perfectamente el palco que se ubica a un nivel más bajo en la sala declinada. Sobre él, coloqué las mismas palabras en guaraní que referí antes, en vinilo adhesivo color blanco, y en un diseño similar. $Y$ compuse una pieza sonora a partir de la grabación de vidrios quebrándose y cayendo al suelo, hierros torciéndose y sonidos de ópera, en colaboración con un músico argentino. Este concierto experimental fue diseñado en sistema cuadrafónico para genera en los visitantes la impresión de estar asistiendo al derrumbe del edificio.

P. A Residência Artística que você realizou em 2008, na cidade se Barcelona, aproxima-se do trabalho realizado em Curitiba, em 2011, quanto ao aspecto da vivência do espaço que você teve e com o trabalho apresentado. Conte-nos sobre o trabalho nessa residência.

R. Allí realicé una serie de obras que titulé Patinar en el MACBA - Museu d'Art Contemporani de Barcelona, que muestra al museo transformado en un ámbito de conflicto, entre los skaters, que se han apropiado de algunos de sus espacios exteriores, y la policía, que debe hacer cumplir la ordenanza que dispone "fomentar y garantizar la convivencia ciudadana en el espacio público de Barcelona". 
Da cuenta de ello la instalación que realicé con un skateboard que compré a un patinador en la explanada del museo y al que añadí una pequeña pantalla que reproduce un video que documenta la situación. Tiene además una serie de elementos interrelacionados que crean una atmósfera que lo complementa, como es una gorra y un chaleco de Mosso d' Escuadra y un libro de arquitectura (adquirido en la tienda del MACBA) que muestra al museo despoblado.

Otra instalación, representa la guardia policial que vigila frente al museo. La hice valiéndome de elementos disímiles, como una fotografía del edifico, dos figurillas de policía y un automóvil de colección, dispuestos a diferentes distancia sobre un trípode sujeto a la pared. Estos elementos, sin guardar relación de escala entre ellos, se aúnan en perfecta perspectiva al ser observados mediante un monocular invertido.

También construí una estructura de 3 niveles, que tiene en la parte superior un cartel con la forma de un skateboard que lleva troquelada la leyenda SKATEBOARDING CONTROL, la que iluminada proyectar la inscripción en grandes dimensiones sobre la pared. $Y$ que contiene en la parte media una porra de policía y en la base algunos posters y catálogos editados por el museo.

Hice además un objeto, a la manera de un souvenir de la tienda del museo, con figuras de policías y monopatinadores a escala $1: 87$, los que organicé dentro de una caja plástica diminuta con la identidad gráfica del MACBA en los laterales.

Una serie de fotografías completan este proyecto.

P. Há uma presença de site specific em alguns de seus trabalhos como, por exemplo, "O fogo no museu" realizado nos EUA (2010). Como você os reapresenta em outros espaços que não o de origem?

R. Fire in the museum fue una intervención a escala monumental en la fachada del Museo de Arte de las Américas dependiente de la OEA, en Washington DC, con un diseño de humo y llamas en vinilo adhesivo saliendo de sus ventanas, para significar el peligro que representa para un museo funcionar en una casa histórica (1911) por las características combustibles de su estructura.

En 2011, exhibí en la Galería Baro de Sao Paulo, Brasil, los planos del museo intervenidos con el diseño del fuego, la documentación en video del montaje en Washington DC y el plotagem de unas ventanas en llamas sobre las paredes del espacio expositivo, similares a las del museo en forma y tamaño. 
Con ello quise significar las diferentes maneras que tenemos de percibir el mismo trabajo según el contexto, ya que en el pasado Brasil sufrió dos perdidas irremplazables por el fuego. El 8 de Julio de 1978, un pavoroso incendio destruyó el Museo de Arte Moderno de Río de Janeiro reduciendo a cenizas su valioso patrimonio. $Y$ más recientemente, el 17 de octubre de 2009, un incendio destruyó gran parte del acervo artístico y documental del artista brasileño Helio Oiticica (1937-1980) el cual se albergaba en una casa privada en Río de Janeiro bajo la tutela de su familia.

P. Como você descreve sua relação entre o museu, as instituições de arte, e seus trabalhos?

R. Mi relación con el espacio institucional del arte y su estructura de funcionamiento comenzó tempranamente, a los 14 años como voluntario de museo y me llevó a convertirme en coordinador de exhibiciones a los 19 y en director del Museo de Bellas Artes de Tandil a los 23.

Esa experiencia sorteando los asuntos que rodean el trabajo en un museo me motivó a crear un arte propio en donde dar salida a este tipo de temas, que difícilmente podría haber entendido completamente si no los hubiera vivido desde dentro. Es por eso que algunas de mis obras tienen un sentido autobiográfico, recuerdan mi experiencia como director de museo y la influencia que diferentes instituciones han tenido en mi formación, mi carrera y mi vida.

P. No trabalho "Entre Bienais" (Bienal do Vento Sul, Curitiba, 2011), você fez uma curadoria independente onde selecionou 14 vídeos de artistas argentinos e está apresentando dentro de algumas linhas ônibus de viagem e aviões no trajeto Curitiba - Porto Alegre. Quais critérios você adotou para selecionar estes artistas e seus trabalhos?

R. Comencé investigando la mayor cantidad posible de obras audiovisuales de artistas argentinos, tanto de trayectoria como emergentes, incluso cuando el video no fuese su principal medio de expresión. Me centré en obras monocanal, dado que el dispositivo de exhibición serían las pantallas de los circuitos cerrados de televisión de ônibus y aviones. Usé un criterio muy personal, seleccionando obras muy diversas que despertaron en mí el interés en sus planteamientos y en sus intenciones, y que reflejan las particularidades de cada uno de los artistas. 
Como nota, el sonido no es algo menor en la mayoría de ellas. Tampoco el orden de los videos es arbitrario; es un diagrama de intensidades que busca mantener la atención del espectador durante toda la exhibición.

P. O que acontece com os trabalhos anteriores? Você continua a utilizá-los modificando alguma coisa? Como o projeto "Entre Bienais" onde você apresentou um trabalho com o mesmo conceito no Chile e agora no Brasil?

R. Los proyectos a los que usted refiere tienen puntos en común y también algunas diferencias. La I Trienal de Chile (2009), curada por Ticio Escobar bajo el título "Los Límites del Arte", se desplegaba en siete ciudades, de Antofagasta a Valdivia, con exhibiciones y coloquios que utilizaban la infraestructura pública existente, como los museos. Pensé entonces en todo aquello que quedaba afuera del circuito establecido, tanto por los límites institucionales como los geográficos mencionados. Fue entonces que decidí poner mis producciones audiovisuales en los circuitos cerrados de TV de autobuses públicos de media y larga distancia para alcanzar todo el territorio nacional, más de 2 millones de kilómetros cuadrados, llegando así a sitios completamente aislados de toda presencia de museos, galerías o instituciones similares. "Entre Bienales" es una exposición que se mueve entre la 6a Ventosul Bienal de Curitiba y la 8a Bienal del Mercosur de Porto Alegre, en Brasil. Se trata de 14 obras audiovisuales de artistas argentinos que seleccioné para los circuitos cerrados de televisión de autobuses y aviones públicos que hacen el viaje entre Curitiba y Porto Alegre. La intención fue reflexionar sobre los límites de estas bienales que están geográficamente próximas, que ocurren al mismo tiempo, pero que no tienen ningún vínculo entre ellas. La Bienal de Curitiba, curada por Alfons Hug y Ticio Escobar, lleva por título "Más allá de la Crisis" y la Bienal del Mercosur, curada por José Roca, se titula "Geopoéticas". Es así que "Entre Bienales" no solo se mueve entre ambas ciudades sino también entre ambos conceptos.

\section{P. Há situações em que você utliza o trabalho de curadoria como uma espécie de} laboratorio para o seu próprio trabalho artístico?

R. Encuentro en la curaduría una práctica en la que puedo cristalizar ideas, como en mis obras. Es así que al momento de pensar en ella lo hago también apasionadamente, empujando sus bordes en todas las direcciones posibles; y teniendo en cuenta el contenido, el contenedor y el continente. "Entre Bienales", por ejemplo, puede leerse como una curaduría de obras audiovisuales de arte argentino actual, con su propio andamiaje interno, que es a su vez una intervención a gran escala para hacer un comentario crítico sobre dos Bienales próximas geográficamente y sin vínculos entre ellas, al tiempo que explora un 
ámbito no convencional de exhibición en los circuitos cerrados de TV de ómnibus y aviones, y que va al encuentro de un público diverso, además de el del mundo del arte.

\section{P. Quais são suas referências artísticas e intelectuais e como estas afetam seu processo criativo?}

R. El escritor argentino Jorge Luis Borges (1899-1986) es un autor que continuamente releo, por el gusto de construir mentalmente sus escenarios una y otra vez. Su influjo subyace en algunos de mis trabajos, aunque de un modo sutil, casi secreto.

Tengo además una gran admiración por el artista argentino Víctor Grippo (1936-2002), de quien en el año 2002 compilé un libro que me permitió conocer con mayor profundidad su trabajo. Mis obras Valijita de ex director de museo (2003) y Mesa de trabajo y reflexión (2009) lo celebran.

Extraño parecerá encontrar su influencia en mi obra actual, pero no hay que buscarla en lo formal, sino que parte de mi desarrollo posiblemente esté ligado a lo que me ha trasmitido su ética como también la calidad reflexiva y la sensibilidad de su trabajo, de una notable carga poética y una realización tremendamente refinada.

\section{P. De que forma essas obras que você citou se identificam com o artista Victor Grippo?}

R. La primera, es una obra que realicé al finalizar mi gestión al frente de la dirección del Museo de Bellas Artes de Tandil. En ella reproduzco a escala el museo, al modo de un maletín de funcionario público, de cartón, cubierto por una pintura de apariencia metálica y con una "manija" sin quién la sostenga. Ironiza sobre la falta de continuidad en las políticas culturales trazadas en dicha institución. Realidad común a muchas otras instituciones argentinas cuando se renuevan sus funcionarios, principalmente si cambia el color político. La produje al año siguiente de la publicación del libro de Víctor Grippo y puede asociarse con sus valijas, las que en su trabajo están presentes desde 1972 con su Propuesta para una serie un tanto apocalíptica (arqueología perspectiva) y se extienden hasta 1980 con Valijita de albañil, última con este formato.

La segunda, es una mesa de madera con la forma de mi perfil derecho. La mesa: objeto genérico, mi lugar de trabajo. La cabeza: el espacio mental, el de las ideas, el de la conciencia. Una interacción entre el hacer sobre una mesa y el pensamiento, donde se modifica la material y el espíritu en un mismo acto.

Su título, en singular, alude a una de las obras más significativas de Grippo: Mesas de trabajo y reflexión (1994), realizadas para la quinta Bienal de La Habana con mesas 
escolares y de otros usos. Lilian Llanes cuenta que mientras otros artistas arribaban con sus obras a la isla, Grippo llegó con las manos vacías, "como si quisiera decir que los medios no eran importantes; que mientras hubieran ideas, todo era posible".

P. Observamos que alguns de seus trabalhos possuem uma ligação direta com as instituições da arte, possuindo em certos momentos, um caráter de auto-retrato ou uma referência sobre o tema.

R. Como mencionaba antes, Valijita de ex director de museo es una obra que excede lo autorreferencial para hablar de un problema común a muchas instituciones del arte en Argentina. Mesa de trabajo y reflexión, es un autorretrato. Existen dos versiones de esta obra. Una es el objeto tridimensional. La otra, una fotografía del objeto. Alude a mi espacio de trabajo y reflexión. Como retrato, se inserta en una larga tradición en la historia del arte en la cual se ve a la persona acompañada de sus atributos personales o profesionales y que revelan sus gustos o actividad. En mi caso he seleccionado la mesa de trabajo donde elaboro la mayor parte de mis obras y proyectos. $Y$ he elegido un marco antiguo muy elaborado con diseños en relieve para enmarcar la imagen. De este modo conecto mi obra actual con retratos que revelan su importancia a través de la riqueza de los marcos que lo adornan. La curadora Alma Ruiz considera que "el contraste entre la simple mesa de madera y el elegante marco subraya dos aspectos en la carrera de un artista: el trabajo arduo y diario que conlleva la creación artística y la fama real o imaginaria que lo acompaña".

P. Pensando no conjunto dos trabalhos que você produziu até o momento, você consegue perceber elementos em comum que persistem nas suas obras? Poderias elencar algum?

R. Utilizo en mis obras distintos medios como el dibujo, la fotografía, el objeto, la instalación, la edición, el video, la video-instalación, el arte sonoro, el cruce de los mismos y la interacción y diálogo con otras disciplinas.

Lo que persiste en mi trabajo es precisamente la diversidad de medios empleados y el desarrollo de conceptos relacionados, generalmente, al espacio institucional del arte y sus diversas problemáticas.

\section{P. Como você pensa o material que será utilizado para a confecção do trabalho?}

R. Los materiales que utilizo son muy variados, no pensados a priori, sino que aparecen (y en ocasiones también cambian) durante el proceso de trabajo. Cada proyecto arroja su propia materialidad. 


\section{P. Qual o momento em que você sente a necessidade de partir para um novo trabalho?}

R. Puede ocurrir en cualquier momento. Estoy siempre dispuesto a generar ideas para nuevos trabajos. Por esa razón, habitualmente avanzo en varios proyectos al mismo tiempo. Es así que cuando finalizo uno, otros ya están en proceso. $\mathrm{Y}$ el orden en que les doy comienzo no determina necesariamente cual concluiré primero.

\section{P. Quais os projetos que você está realizando atualmente?}

R. Te contaré de dos proyectos que acontecerán próximamente en Cuba y en México, respectivamente. El primero, es para la Oncena Bienal de La Habana, que tendrá lugar del 11 de mayo al 11 junio de este año. Se titula Cabina de Exhibición Audiovisual y se trata de una doble cabina de proyección, de uso individual, que he diseñado para el Pabellón Cuba, en la que exhibiré un video propio y el de otros 10 artistas que he invitado para la ocasión. Ellos son Regina Silveira (Brasil), Lucas Bambozzi (Brasil), Narda Alvarado (Bolivia), Elia Alba (Republica Dominicana / NY), Mario Opazo (Colombia), Alfredo Ramos y Kasia Badach (Cuba), Silvia Rivas (Argentina), Nicolás Rupcich (Chile) y Yoshua Okón (México). Además, los videos serán compilados en un disco DVD que distribuiré gratuitamente para ser visto en el ámbito domestico cubano.

El otro, es un proyecto para una exposición que sucederá en el Museo Carrillo Gil de México. Se trata de un trabajo de una gran densidad simbólica, que involucra en su producción a la escultura, la performance, el video y la intervención, y que presentaré al modo de una video instalación específica para el sitio. Para ello estoy esculpiendo en piedra mi cabeza, a escala 1:1. Con ella realizaré una performance en una de las salas, lanzándola contra las paredes con la mayor fuerza posible, en reiteradas ocasiones, hasta agotar toda mi energía. Los choques, dejarán marcas en los muros y en el suelo del museo. También la cabeza sufriría daños por los golpes. Para la exposición, la escena quedará tal cual ha sucedido, con la cabeza y sus restos en el suelo. $Y$ a pocos metros, proyectaré el video registro en cámara lenta, puntualizando en mi esfuerzo, en el ímpetu de los golpes y de las caídas. 